\section{Estratégia Saúde da Família e internações hospitalares em menores de 5 anos no Piauí, Brasil}

\author{
The Family Health Strategy and hospital admissions \\ of children under five years in Piauí State, Brazil
}

\footnotetext{
1 Secretaria Municipal de Saúde de Piripiri, Piripiri, Brasil.

2 Christus Faculdade do Piauí, Piripiri, Brasil. 3 Universidade Federal do Piauí, Teresina, Brasil.

${ }^{4}$ Universidade Estadual do Piauí, Teresina, Brasil.

5 Secretaria Municipal de Saúde de Parnaíba, Parnaíba, Brasil.

Correspondência J. O. M. Barreto Secretaria Municipal de Saúde de Piripiri.

Praça da Bandeira 221, Piripiri, PI 64260-000, Brasil. jorgeomaia@hotmail.com
}

\begin{abstract}
Hospitalizations for some health conditions can be reduced by timely primary care with appropriate quality, especially in children. This study analyzed the trend in hospitalizations in children under five years of age in Piaui State, Brazil, from 2000 to 2010, according to groups of causes (ICD10) and hospital admissions in 2010, based on the Brazilian List of Hospitalizations for Primary Care-Sensitive Conditions. The objectives were to identify changes in the hospital morbidity profile and to discuss their relationship to expansion of the Family Health Strategy (FHS) in the State. Piaui showed the highest proportional expansion of the FHS in Brazil, reaching an estimated coverage of $97.2 \%$ in 2010. From 2000 to 2010, there was a reduction in the hospitalization frequency and rates in children under five years, but the proportion of hospitalizations in the leading groups of causes persisted or increased during the decade. In 2010, 60\% of hospitalizations in children under five years were for causes that are sensitive to primary care, especially infectious gastroenteritis, respiratory infections, and asthma.
\end{abstract}

Primary Health Care; Hospitalization; Child Health
Jorge Otávio Maia Barreto 1,2

Inez Sampaio Nery 3

Maria do Socorro Candeira Costa 4,5

\section{Introdução}

A atenção primária à saúde é apontada em todo o mundo como a estratégia mais efetiva para a universalização do acesso à saúde 1 , porém os melhores resultados são obtidos quando os sistemas de saúde estão adequadamente estruturados para garantir esta atenção como primeiro nível de assistência integral e contínua com qualidade 2 . No Brasil, a Estratégia Saúde da Família (ESF) é o modelo nacional de atenção primária à saúde, definido pela Política Nacional de Atenção Básica (PNAB) 3,4, e inclui entre suas diretrizes além da integralidade, atributos de coordenação da assistência, centralidade na família, orientação e participação comunitária e competência cultural dos profissionais de saúde, visando à efetivação dos atributos essenciais da atenção primária à saúde 2,5 , a fim de alcançar a resolutividade desejada em face dos principais problemas de saúde da população.

Em todo o país, a ESF vem ampliando sua abrangência desde 1994, quando teve início como programa do Ministério da Saúde com o objetivo de reorganizar os sistemas locais de saúde para a superação do modelo assistencialista hospitalocêntrico vigente 4 , concretizando os princípios constitucionais do Sistema Único de Saúde (SUS) de universalidade, integralidade e equidade. Em dezembro de 2010, quase todos os municípios do Brasil apresentavam equipes implantadas e, se considerada a estimativa uti- 
lizada pelo Ministério da Saúde de 3.450 pessoas acompanhadas por equipe, $52,2 \%$ da população brasileira estariam cobertas pela ESF, sendo que os estados nordestinos apresentariam as maiores coberturas populacionais estimadas (http:// dtr2004.saude.gov.br/dab/historico_cobertura_ sf.php, acessado em 23/Ago/2011).

O Estado do Piauí, localizado no Nordeste do Brasil, passou por relevante evolução quantitativa da ESF durante a década de 2000, passando a apresentar a maior cobertura populacional estimada do país. Em 2010, quase 1.100 equipes da ESF estariam potencialmente cobrindo mais de 3 milhões de piauienses em serviços de atenção primária à saúde, os quais, a tomar-se como referência normativa a $\mathrm{PNAB}^{3}$, deveriam estar garantindo atenção oportuna e com qualidade. Apesar da presença da ESF em todos os municípios do Piauí, ainda não estão devidamente clarificados os efeitos da ESF nos diversos contextos locais, em especial quanto aos impactos sobre as condições de saúde da população.

Embora haja estudos acerca do impacto da ESF em nível nacional, especialmente na saúde infantil 6,7,8,9,10, avaliações no nível estadual, em especial para o Nordeste, são pouco disponíveis, especialmente para análise de desempenho da ESF em suas múltiplas dimensões de atuação. Estudos avaliativos, de uma forma geral, têm sua relevância reconhecida e podem adotar diversas abordagens, com base em marcos teóricos diversificados, para evidenciar diferentes dimensões de uma política ou programa, entretanto, a avaliação de desempenho representa uma abordagem que busca identificar resultados relacionados com a política avaliada a partir da mensuração de seus resultados 11,12.

Medidas de desempenho podem ser obtidas com suporte em indicadores ou indicadores relacionados com condições potencialmente afetadas pelas ações de uma política ou programa social 10,11. No caso da ESF, o acesso e a qualidade da atenção podem ser monitorados com base em variáveis de mortalidade e morbidade, mediante a identificação e monitoramento dos óbitos e adoecimentos por causas potencialmente influenciadas pela presença da atenção primária à saúde 13,14. A morbidade hospitalar causada por condições sensíveis à atenção primária à saúde consiste em um conjunto de problemas de saúde, para os quais ações efetivas poderiam reduzir a frequência destas internações, alterando também seu perfil epidemiológico 13. Assim, internações hospitalares consideradas evitáveis pela ação oportuna de serviços de atenção primária à saúde poderiam ser usadas como indicador de resultado para avaliação da qualidade e do acesso nesse nível de atenção 13,15,16.
Algumas investigações abordaram a relação entre as internações hospitalares e a atenção ambulatorial, a fim de configurar indicador de qualidade e acesso aos serviços de saúde baseando-se no perfil das hospitalizações 13,15,16,17,18. No Brasil, partindo do marco conceitual de que a atenção primária à saúde oportuna e de boa qualidade pode evitar a hospitalização relacionada com algumas condições de saúde e reduzir a sua frequência 16, Alfradique et al. 18 apresentaram uma lista brasileira do Projeto ICSAP - Brasil (internações por condições sensíveis à atenção primária), com a finalidade de auxiliar a avaliação do desempenho dos sistemas de saúde e os impactos da atenção primária sobre as condições de saúde da população. A lista oficial brasileira do Projeto ICSAP foi lançada em abril de 2008, pela Secretaria de Atenção à Saúde do Ministério da Saúde, com dezenove grupos de diagnósticos classificados de acordo com a 10a revisão da Classificação Internacional de Doenças (CID-10), abrangendo as causas mais frequentes de internações hospitalares no âmbito do SUS 19.

Considerando que altas taxas de internações por condições sensíveis à atenção primária em uma população, ou subgrupos desta, podem significar problemas de acesso aos serviços de saúde ou no seu desempenho ${ }^{18}$, o monitoramento dessas hospitalizações poderia apoiar a tomada de decisão para enfrentar o excesso de internações evitáveis.

O grupo etário menor de 5 anos está entre os mais vulneráveis às determinantes sociais da saúde, dentre as quais se inclui, além de outras variáveis de natureza socioeconômica, o acesso aos serviços de saúde 20. Quanto ao papel dos serviços de saúde no nível da atenção primária sobre a saúde infantil, Harzheim et al. 5, ao compararem modelos de assistência com base nos atributos de qualidade e acesso da atenção primária à saúde, observaram que onde os serviços se alinhavam a estes atributos se obteve melhores resultados nos indicadores de saúde a menor custo, inclusive para a redução de internações hospitalares por condições sensíveis à atenção primária à saúde em crianças, além de maior satisfação dos usuários quanto à resolução dos serviços.

Este trabalho analisa, de forma geral, a evolução das internações hospitalares do SUS em crianças menores de 5 anos, no período de 2000 a 2010, no Estado do Piauí, e, de forma específica, as internações hospitalares, na mesma faixa etária, ocorridas no ano de 2010, com base na lista brasileira oficial do Projeto ICSAP 19. O objetivo foi identificar mudanças na situação de saúde infantil no Piauí quanto ao perfil de morbidade hospitalar e discutir sua relação com a expan- 
são da ESF no estado, contribuindo, assim, com a discussão mais ampla sobre as informações e metodologias adequadas às avaliações do desempenho da ESF em nível subnacional.

\section{Métodos}

Trata-se de um estudo quantitativo de abordagem ecológica, na sua primeira parte, e transversal, no segundo momento. Inicialmente, com o objetivo levantar hipóteses sobre a associação entre a implementação da ESF e a morbidade hospitalar infantil no Piauí, fez-se a retrospectiva da evolução da cobertura estimada da ESF, de 2000 a 2010, com base na situação registrada no mês de dezembro de cada ano da série. Os dados da cobertura da ESF foram obtidos no sítio do Ministério da Saúde na Internet, na área do Departamento de Atenção Básica da Secretaria de Assistência à Saúde (http://dtr204.saude.gov.br/ dab/historico_cobertura_sf.php, acessado 23/ Ago/2011).

A população assistida e a cobertura populacional utilizadas foram estimadas segundo os parâmetros adotados pelo Ministério da Saúde 6 . Em seguida, foram coletados dados da base do Sistema de Informações Hospitalares do SUS (SIH/SUS) sobre internações hospitalares de residentes no Piauí menores de 5 anos, de 2000 a 2010, considerando-se as faixas etárias específicas de menores de 1 ano e 1-4 anos, as quais foram classificadas quanto ao diagnóstico, segundo os capítulos da CID-10. Mediante análise estatística descritiva, foram identificados os três grupos de causas de internações hospitalares mais frequentes e calculadas as suas proporções e taxas de internação, ao longo da série histórica. Foi, então, analisada a correlação linear entre a evolução das internações hospitalares nos grupos de causas destacados e a cobertura populacional estimada da ESF no estado, mediante a determinação do coeficiente de correlação de Pearson. A análise estatística foi realizada com o auxílio do TabWin (Departamento de Informática do SUS. http://portal.saude.gov.br/portal/ se/datasus/area.cfm?id_area=732) e Excel (Microsoft, Estados Unidos) e os resultados foram dispostos em tabelas.

Na segunda parte do trabalho, adaptando o método descrito por Moura et al. 15 , procedeu-se à análise transversal das internações hospitalares nas faixas etárias escolhidas no ano de 2010, com base na lista brasileira oficial do Projeto ICSAP 19, objetivando caracterizar o perfil de hospitalização infantil daquele ano quanto à sensibilidade às ações de atenção primária à saúde. Foram identificadas e distribuídas por frequência as interna- ções hospitalares segundo os grupos de causas na faixa etária de menores de 5 anos. Calculou-se a proporção de ICSAP no total das internações hospitalares na faixa etária escolhida, bem como as taxas de internação (por 10 mil habitantes) em cada grupo de causas identificado. Nessa etapa, utilizaram-se os dados populacionais divulgados pelo Instituto Brasileiro de Geografia e Estatística (IBGE; (http://www.ibge.gov.br/estadosat/ temas.php?sigla $=$ pi\&tema $=$ sinopse_censode mog2010, acessado em 30/Abr/2011). A série foi classificada em ordem decrescente, segundo as taxas de internação em cada grupo de diagnóstico, identificando-se os três grupos de causas de ICSAP mais relevantes para a internação hospitalar em menores de 5 anos no Piauí, no ano de 2010.

Esta análise utilizou dados secundários de bases oficiais, não havendo implicações éticas quanto à abordagem de seres humanos. Buscouse, entretanto, seguir todos os princípios de confidencialidade de informações recomendados pela Resolução $n^{o}$. 196/96 do Conselho Nacional de Saúde.

\section{Resultados}

A Tabela 1 apresenta a evolução da ESF no Piauí, no período de 2000-2010, mostrando o total de municípios que implantou equipe da ESF, o número total de equipes no estado, bem como a estimativa nominal da população coberta e o porcentual estimado da população assistida, segundo o Ministério da Saúde. Ao longo da década, o número de equipes implantadas foi aumentado em $166 \%$ e a estimativa de cobertura populacional em 93,6\%. Em 2010, o Piauí contava com 1.099 equipes da ESF implantadas, correspondentes à cobertura populacional estimada próxima de $100 \%$.

A Tabela 2 mostra que as causas de internação mais frequentes em menores de 1 ano no Piauí, entre os anos de 2000 e 2010, foram as doenças do aparelho respiratório, seguidas das doenças infecciosas e parasitárias e afecções perinatais. As demais causas de hospitalizações juntas representaram $12 \%$ do total no período analisado. Houve redução geral da frequência das internações de crianças menores de 1 ano nos dois principais grupos de causas (doenças do aparelho respiratório e doenças infecciosas e parasitárias) sendo que estes mostraram crescimento proporcional no período analisado. As afecções perinatais, por outro lado, apesar da pouca variação da frequência, tiveram proporção aumentada, chegando a $25 \%$ das internações de menores de 1 ano, em 2010. 
Evolução da cobertura da Estratégia Saúde da Família (ESF). Piauí, Brasil, 2000-2010.

\begin{tabular}{lcccc}
\hline Ano & Municípios com ESF & $\begin{array}{c}\text { Equipes da ESF } \\
\text { implantadas }\end{array}$ & $\begin{array}{c}\text { População assistida } \\
\text { estimada * }\end{array}$ & $\begin{array}{c}\text { Cobertura populacional } \\
\text { estimada (\%) }\end{array}$ \\
\hline 2000 & 189 & 413 & 1.373 .012 & 50,2 \\
2001 & 205 & 566 & 1.813 .678 & 63,1 \\
2002 & 217 & 704 & 2.196 .692 & 76,4 \\
2003 & 218 & 761 & 2.312 .518 & 79,8 \\
2004 & 217 & 861 & 2.583 .245 & 87,7 \\
2005 & 221 & 980 & 2.805 .604 & 95,2 \\
2006 & 222 & 1.028 & 2.936 .229 & 96,0 \\
2007 & 222 & 1.032 & 2.934 .290 & 95,0 \\
2008 & 222 & 1.069 & 2.981 .397 & 96,6 \\
2009 & 221 & 1.088 & 3.036 .005 & 97,3 \\
2010 & 223 & 1.099 & 3.056 .879 & 97,2 \\
\hline
\end{tabular}

* População assistida e cobertura populacional estimadas pelo Ministério da Saúde.

Fonte: Departamento de Atenção Básica, Secretaria de Atenção à Saúde, Ministério da Saúde.

Tabela 2

Internações hospitalares de residentes menores de 1 ano de idade por capítulo da 10ạ revisão da Classificação Internacional de Doenças (CID-10). Piauí, Brasil, 2000-2010.

\begin{tabular}{|c|c|c|c|c|c|c|c|c|c|c|c|c|c|c|}
\hline \multirow[t]{3}{*}{ Ano } & \multicolumn{12}{|c|}{ Internações hospitalares por capítulo da CID-10 } & \multirow{2}{*}{\multicolumn{2}{|c|}{$\begin{array}{c}\text { Total de } \\
\text { internações } \\
\text { hospitalares } \\
\text { (<1 ano) }\end{array}$}} \\
\hline & \multicolumn{3}{|c|}{$\begin{array}{l}\text { X. Doenças do aparelho } \\
\text { respiratório }\end{array}$} & \multicolumn{3}{|c|}{$\begin{array}{c}\text { I. Algumas doenças } \\
\text { infecciosas e parasitárias }\end{array}$} & \multicolumn{3}{|c|}{$\begin{array}{l}\text { XVI. Algumas afecções } \\
\text { originadas no período } \\
\text { perinatal }\end{array}$} & \multicolumn{3}{|c|}{$\begin{array}{l}\text { Outros capítulos da } \\
\text { CID-10 }\end{array}$} & & \\
\hline & $\mathbf{n}$ & $\%$ & $\mathrm{Tx} *$ & $\mathbf{n}$ & $\%$ & $\mathrm{Tx} *$ & $\mathbf{n}$ & $\%$ & $\mathrm{Tx}$ * & $\mathbf{n}$ & $\%$ & $\mathrm{Tx} *$ & $\mathbf{n}$ & $\mathrm{Tx} *$ \\
\hline 2000 & 5.773 & 38,5 & 992,5 & 5.142 & 34,3 & 884,0 & 2.381 & 15,9 & 409,3 & 1.699 & 11,3 & 292,1 & 14.995 & 2577,9 \\
\hline 2001 & 5.272 & 36,3 & 897,0 & 5.011 & 34,5 & 852,6 & 2.700 & 18,6 & 459,4 & 1.528 & 10,5 & 260,0 & 14.511 & 2468,9 \\
\hline 2002 & 4.438 & 34,1 & 748,5 & 4.940 & 38,0 & 833,2 & 2.125 & 16,3 & 358,4 & 1.514 & 11,6 & 255,4 & 13.017 & 2195,5 \\
\hline 2003 & 5.032 & 40,6 & 841,2 & 4.070 & 32,8 & 680,4 & 1.984 & 16,0 & 331,7 & 1.313 & 10,6 & 219,5 & 12.399 & 2072,9 \\
\hline 2004 & 3.499 & 32,6 & 579,9 & 3.998 & 37,2 & 662,6 & 2.047 & 19,1 & 339,2 & 1.189 & 11,1 & 197,0 & 10.733 & 1778,7 \\
\hline 2005 & 4.202 & 38,9 & 683,1 & 3.461 & 32,1 & 562,6 & 2.025 & 18,8 & 329,2 & 1.107 & 10,3 & 179,9 & 10.795 & 1754,8 \\
\hline 2006 & 2.769 & 27,9 & 445,7 & 3.699 & 37,3 & 595,4 & 2.332 & 23,5 & 375,4 & 1.130 & 11,4 & 181,9 & 9.930 & 1598,4 \\
\hline 2007 & 3.630 & 37,7 & 572,4 & 2.534 & 26,3 & 399,6 & 2.400 & 24,9 & 378,4 & 1.060 & 11,0 & 167,1 & 9.624 & 1517,5 \\
\hline 2008 & 2.694 & 31,3 & 425,7 & 2.596 & 30,2 & 410,2 & 2.069 & 24,1 & 326,9 & 1.237 & 14,4 & 195,5 & 8.596 & 1358,4 \\
\hline 2009 & 3.558 & 39,5 & 571,0 & 2.187 & 24,3 & 351,0 & 1.943 & 21,6 & 311,8 & 1.327 & 14,7 & 213,0 & 9.015 & 1446,8 \\
\hline 2010 & 2.654 & 31,8 & 566,2 & 2.306 & 27,6 & 491,9 & 2.105 & 25,2 & 449,1 & 1.284 & 15,4 & 273,9 & 8.349 & 1781,1 \\
\hline$r$ & - & - & $-0,90$ & - & - & $-0,88$ & - & - & $-0,45$ & - & - & $-0,71$ & - & $-0,94$ \\
\hline
\end{tabular}

* Taxa de internação por 10 habitantes na faixa etária calculada com base nas informações do Instituto Brasileiro de Geografia e Estatística, Censos Demográficos 2000 e 2010; 2001-2006, estimativas para os anos intercensitários; 2007-2009, estimativas elaboradas no âmbito do Projeto do Fundo Populacional das Nações Unidas/Instituto Brasileiro de Geografia e Estatística (BRA/4/P31A) - População e Desenvolvimento.

Fonte: Sistema de Informações Hospitalares do SUS (SIH/SUS), Ministério da Saúde. 
Quanto às taxas de internação na faixa etária nos grupos de causas destacados, observou-se clara tendência de redução no primeiro e segundo grupos (doenças do aparelho respiratório e algumas doenças infecciosas e parasitárias), respectivamente, mas menor variação no terceiro e quarto grupos (afecções perinatais e demais capítulos da CID-10) que permaneceram praticamente estáveis.

Da análise da correlação linear entre as taxas de internação nos grupos de causas destacados com o avanço da estimativa da cobertura populacional da ESF, percebeu-se associação negativa para todos os grupos analisados, porém, esta se mostrou muito mais forte para as doenças do aparelho respiratório $(\mathrm{r}=-0,90)$ e doenças infecciosas e parasitárias $(\mathrm{r}=0,88)$ do que para as afecções perinatais $(r=-0,45)$, demais capítulos da CID-10 $(r=-0,71)$ e mesmo para hospitalizações gerais na faixa etária $(\mathrm{r}=-0,47)$.

A Tabela 3 apresenta as mesmas variáveis usadas para menores de 1 ano, agora aplicadas à população de 1-4 anos. No grupo etário, as hospitalizações entre 2000 e 2010 se deram principalmente por causas relacionadas com doenças infecciosas e parasitárias, doenças do aparelho respiratório e doenças do aparelho digestivo, nesta ordem. Os demais grupos de diagnóstico se mantiveram em proporção consideravelmente estável (média $=12 \%$, mediana $=11,3 \%$ ), portanto, sem muita variação. O grupo de causas mais relevante nas internações na faixa etária de 1-4 anos foi o de doenças infecciosas e parasitárias, que manteve a relevância proporcional ao longo de toda a década pesquisada. Entretanto, sua magnitude sofreu clara redução ao tempo em que as doenças do aparelho respiratório e do aparelho digestivo apresentaram incremento relevante na proporção que estes grupos de causas representaram no total de hospitalizações na população analisada.

Quanto à associação entre as principais de causas de internações nesse grupo etário e a expansão da cobertura estimada ESF, verificou-se ser negativa muito forte apenas para as taxas do principal grupo de causas, doenças infecciosas e parasitárias $(r=-0,93)$. Nos outros grupos de causas destacados, a associação foi fraca, como observado nas internações por doenças do aparelho respiratório $(\mathrm{r}=-0,37)$, ou mesmo inexistente, tal como nas hospitalizações infantis por doenças do aparelho digestivo $(r=0,07)$. Por fim, verificou-se ser forte a correlação negativa entre a expansão da cobertura populacional estimada da ESF e o histórico das taxas de internação relacionadas com os demais capítulos da CID-10 $(\mathrm{r}=-0,94)$, bem como na evolução geral das hospitalizações $(r=-087)$.
A Tabela 4 traz o perfil das internações em menores de 5 anos no Piauí apenas do ano de 2010, considerando sua frequência e proporção, segundo os diagnósticos previstos na lista brasileira oficial do Projeto ICSAP, bem como apresenta as taxas gerais de ICSAP em cada grupo etário. Segundo os dados encontrados, verificouse que, entre crianças menores de 1 ano, quase a metade $(48,6 \%)$ das internações hospitalares ocorridas em 2010 se deveu a causas sensíveis à atenção ambulatorial em nível primário. Dentre a população de 1 a 4 anos, as internações no SUS que se relacionaram com causas preveníveis chegaram $65,5 \%$, e na população geral de menores de 5 anos, pelo menos $60 \%$ das hospitalizações podiam ser classificadas como ICSAP, de acordo com a lista brasileira oficial. As taxas de internação hospitalar, por 10 habitantes na faixa etária, encontradas por causas sensíveis à atenção primária à saúde nas populações analisadas podem ser consideradas altas, sendo de 859,7 para menores de 1 ano, 559,6 para crianças de 1 a 4 anos e 616,4 para menores de 5 em geral.

A Tabela 5 detalha as ICSAP de menores de 5 anos em 2010 no Piauí, destacando os três principais grupos de causas. Verificou-se que a maior parte das internações hospitalares de menores de 5 anos em 2010 se deu por causas previstas no grupo 2 da lista brasileira oficial de ICSAP (gastrenterites infecciosas e complicações) que abrange diagnósticos específicos de desidratação (E86, CID-10) e gastrenterites (A-00 a A-09, CID-10), correspondendo a $32,6 \%$ de todas as internações hospitalares no grupo etário. A taxa de internação para esse grupo de causas foi de 334,58 .

Ainda na Tabela 5, viu-se que as pneumonias bacterianas e a asma apareceram, respectivamente, como o segundo e o terceiro mais importantes grupos de causas de ICSAP. As pneumonias, que correspondem ao grupo 6 da lista brasileira oficial, representaram 12,8\% das hospitalizações e sua taxa de internação foi de 131,22. Os diagnósticos do grupo 7 , relacionados com a asma corresponderam a 9,2\% das internações, com taxa de hospitalização de 95,06. Todas as demais internações de menores de 5 anos devidas aos outros grupos de causas de ICSAP somadas representaram apenas 5,4\% das internações, com taxa de internação específica de 55,59, no ano de 2010.

\section{Discussão}

Num primeiro momento, é adequado discutir as limitações deste estudo. A impossibilidade de incluir informações socioeconômicas, dada 
Internações hospitalares de residentes de 1 a 4 anos de idade por capítulo da 10a revisão da Classificação Internacional de Doenças (CID-10). Piauí, Brasil, 2000-2010.

\begin{tabular}{|c|c|c|c|c|c|c|c|c|c|c|c|c|c|c|}
\hline \multirow[t]{3}{*}{ Ano } & \multicolumn{12}{|c|}{ Internações hospitalares por capítulo da CID-10 } & \multirow{2}{*}{\multicolumn{2}{|c|}{$\begin{array}{c}\text { Total de } \\
\text { internações } \\
\text { hospitalares } \\
\text { (1 a } 4 \text { anos) }\end{array}$}} \\
\hline & \multicolumn{3}{|c|}{$\begin{array}{c}\text { I. Algumas doenças } \\
\text { infecciosas e parasitárias }\end{array}$} & \multicolumn{3}{|c|}{$\begin{array}{l}\text { X. Doenças do aparelho } \\
\text { respiratório }\end{array}$} & \multicolumn{3}{|c|}{$\begin{array}{c}\text { XI. Doenças do aparelho } \\
\text { digestivo }\end{array}$} & \multicolumn{3}{|c|}{$\begin{array}{l}\text { Outros capítulos da } \\
\text { CID-10 }\end{array}$} & & \\
\hline & $n$ & $\%$ & $T x$ * & $n$ & $\%$ & $T x$ * & $\mathrm{n}$ & $\%$ & $T x *$ & $\mathrm{n}$ & $\%$ & $T x$ * & $\mathrm{n}$ & $T x$ * \\
\hline 2000 & 12.966 & 51,1 & 531,9 & 7.660 & 30,2 & 314,2 & 720 & 2,8 & 29,5 & 1.699 & 11,3 & 164,9 & 25.366 & 1040,5 \\
\hline 2001 & 11.779 & 48,3 & 478,3 & 7.771 & 31,9 & 315,5 & 734 & 3,0 & 29,8 & 1.528 & 10,5 & 165,6 & 24.363 & 989,2 \\
\hline 2002 & 11.340 & 46,6 & 456,4 & 8.523 & 35,0 & 343,1 & 910 & 3,7 & 36,6 & 1.514 & 11,6 & 143,5 & 24.339 & 979,6 \\
\hline 2003 & 10.601 & 48,7 & 423,0 & 7.485 & 34,4 & 298,7 & 828 & 3,8 & 33,0 & 1.313 & 10,6 & 113,6 & 21.760 & 868,3 \\
\hline 2004 & 8.990 & 43,6 & 355,6 & 8.107 & 39,3 & 320,7 & 849 & 4,1 & 33,6 & 1.189 & 11,1 & 105,4 & 20.611 & 815,3 \\
\hline 2005 & 8.506 & 44,8 & 330,1 & 7.402 & 39,0 & 287,2 & 780 & 4,1 & 30,3 & 1.107 & 10,3 & 89,8 & 19.001 & 737,3 \\
\hline 2006 & 6.601 & 36,0 & 253,7 & 8.619 & 47,0 & 331,2 & 758 & 4,1 & 29,1 & 1.130 & 11,4 & 91,3 & 18.354 & 705,4 \\
\hline 2007 & 7.513 & 45,4 & 295,1 & 6.114 & 36,9 & 240,2 & 636 & 3,8 & 25,0 & 1.060 & 11,0 & 89,9 & 16.551 & 650,1 \\
\hline 2008 & 6.184 & 38,6 & 242,1 & 6.956 & 43,4 & 272,3 & 669 & 4,2 & 26,2 & 1.237 & 14,4 & 86,9 & 16.030 & 627,5 \\
\hline 2009 & 7.815 & 45,7 & 308,8 & 5.989 & 35,0 & 236,6 & 804 & 4,7 & 31,8 & 1.327 & 14,7 & 98,9 & 17.112 & 676,1 \\
\hline 2010 & 6.876 & 39,9 & 342,7 & 6.730 & 39,0 & 335,4 & 907 & 5,3 & 45,2 & 1.284 & 15,4 & 136,3 & 17.248 & 859,6 \\
\hline$r$ & - & - & $-0,93$ & & & $-0,37$ & & & 0,07 & & & $-0,85$ & & $-0,87$ \\
\hline
\end{tabular}

* Taxa de internação por 10 habitantes na faixa etária calculada com base nas informações do Instituto Brasileiro de Geografia e Estatística, Censos Demográficos 2000 e 2010; 2001-2006, estimativas para os anos intercensitários; 2007-2009, estimativas elaboradas no âmbito do Projeto do Fundo Populacional das Nações Unidas/Instituto Brasileiro de Geografia e Estatística (BRA/4/P31A) - População e Desenvolvimento.

Fonte: Sistema de Informações Hospitalares do SUS (SIH/SUS), Ministério da Saúde.

Tabela 4

Internações em residentes menores de 5 anos, frequência, percentual e taxa/10 mil habitantes na faixa etária, segundo a lista brasileira do Projeto ICSAP. Piauí, Brasil, 2010.

\begin{tabular}{|c|c|c|c|}
\hline \multirow[t]{2}{*}{ Variável } & \multicolumn{3}{|c|}{ Faixa etária (anos) } \\
\hline & $<1$ & $1-4$ & $>5$ \\
\hline População na faixa etária em 2010 (IBGE) & 46.875 & 200.656 & 247.531 \\
\hline Total de internações de < 5anos residentes por faixa etária & 8.287 & 17.155 & 25.442 \\
\hline Total de ICSAP de < 5anos residentes por faixa etária* & 4.030 & 11.229 & 15.259 \\
\hline Porcentual de ICSAP por faixa etária & $48,6 \%$ & $65,5 \%$ & $60,0 \%$ \\
\hline Taxa de ICSAP/10 mil habitantes na faixa etária & 859,7 & 559,6 & 616,4 \\
\hline
\end{tabular}

ICSAP: internações hospitalares por condições sensíveis à atenção primária.

* Segundo a lista brasileira oficial do Projeto ICSAP.

Fonte: Sistema de Informações Hospitalares do SUS (SIH/SUS), Ministério da Saúde/Instituto Brasileiro de Geografia e Estatística (http://www.ibge.gov.br/estadosat/temas.php?sigla=pi\&tema=sinopse_censodemog2010, acessado em 30/Abr/2011). 
Principais grupos de causas de internações hospitalares por condições sensíveis à atenção primária (ICSAP) de menores de 5 anos. Piauí, Brasil, 2010.

\begin{tabular}{|c|c|c|c|}
\hline Grupos de causas de ICSAP * & $\begin{array}{c}\text { Total de ICSAP na faixa } \\
\text { etária }\end{array}$ & $\begin{array}{l}\text { Percentual de ICSAP na } \\
\text { faixa etária }\end{array}$ & $\begin{array}{l}\text { Taxa de ICSAP por grupo } \\
\text { de causa na faixa etária ** }\end{array}$ \\
\hline Grupo 2 - gastrenterites infecciosas e complicações & 8.282 & 32,6 & 334,6 \\
\hline Grupo 6 - pneumonias bacterianas & 3.248 & 12,8 & 131,2 \\
\hline Grupo 7 - asma & 2.353 & 9,2 & 95,0 \\
\hline Outros grupos de causas de ICSAP & 1.376 & 5,4 & 55,6 \\
\hline
\end{tabular}

* Grupos de causas da lista brasileira oficial de ICSAP;

** Taxas de internação calculadas por 10 mil habitantes na faixa etária específica.

Fontes: Sistema de Informações Hospitalares do SUS (SIH/SUS), Ministério da Saúde/Instituto Brasileiro de Geografia e Estatística (http://www.ibge.gov.br/ estadosat/temas.php?sigla=pi\&tema=sinopse_censodemog2010, acessado em 30/Abr/2011).

a natureza das informações utilizadas, pode representar barreira ao aprofundamento da análise quanto à contextualização dos resultados. Esse aspecto é especialmente relevante para avaliações do desempenho, especialmente onde coexistem vulnerabilidades socioeconômicas e alta utilização dos serviços públicos de saúde pelos estratos mais pobres da população, como se supõe ocorrer no Piauí e demais estados do Nordeste. O Piauí, segundo dados relativos a 2010 21, apresenta a terceira menor cobertura do país em saúde suplementar para a faixa etária de menos de 5 anos (8,1\%), contrastando com estados mais ricos, como São Paulo (48\%), ou mesmo com a média nacional (32\%). Tal constatação, se não implica o reconhecimento patente, ao menos permite supor que a maior parcela da população infantil é usuária dos serviços públicos de saúde, dentre eles os realizados pela ESF, que apresentou cobertura populacional estimada de $97,2 \%$ no estado, em 2010.

Por outro lado, não se pode considerar baseando-se unicamente na cobertura populacional estimada, que o avanço da ESF no Piauí tenha se dado de forma homogênea nos diversos municípios do estado. Tal levaria a certa confusão dos diferentes resultados obtidos por municípios com características diversificadas, desde o contexto social até a própria configuração material da ESF, com estruturas, processos de trabalho e arranjos organizacionais diferenciados. Assim, tendo-se em conta que a ESF não consiste em categoria estanque, os resultados aqui apresentados não devem ser considerados como homogêneos para todo o estado, pois podem variar segundo as peculiaridades dos cenários municipais diversos, tal como já identificado por Sousa 8 .

Nesse mesmo aspecto, este trabalho não distinguiu a influência que municípios com po- pulações diferentes podem ter causado sobre a evolução das séries históricas avaliadas. Municípios com grandes concentrações populacionais efetivamente podem influenciar de maneira mais relevante os resultados, porém, em face do contexto demográfico do Piauí, no qual poucos municípios possuem população superior a 50 mil habitantes, apenas cinco, e $63 \%$ da população piauiense se distribuem nos demais, sendo que $88,8 \%$ dos municípios têm menos de 20 mil habitantes (IBGE; http://www.ibge.gov.br/esta dosat $/$ temas.php?sigla $=$ pi\&tema $=$ sinopse_cen sodemog2010, acessado em 23/Ago/2011), pode-se supor que os cenários variam pouco, do ponto de vista demográfico, o que não exclui, entretanto, a possibilidade da capital e os municípios de maior porte influenciarem os resultados de forma diferenciada. Por outro lado, tanto os municípios mais populosos quanto os menores já contavam com coberturas populacionais estimadas da ESF superiores a 95\%, em 2010 (http://189.28.128.100/dab/historico_cobertu ra_nota_tecnica.pdf, acessado em 23/Ago/2011), sendo assim plausível considerar, mesmo que preliminarmente, os resultados gerais como a expressão de realidades relativamente assemelhadas quanto à presença da ESF num estado que, no início da década de 2000, apresentava incidência de pobreza de $53,1 \%$, com extremos municipais de $49,2 \%$ e $56,9 \% 22$.

Deve-se ainda ressaltar que, por se tratarem de dados secundários obtidos em bases de consolidação de informações produzidas de forma descentralizada, os dados utilizados podem conter imprecisões e inconsistências, as quais não foram identificadas nesta análise para fins de ajustamento estatístico.

O Piauí apresentou, em 2010, a maior cobertura estimada da ESF do país, 97,2\%. Diante dis- 
so, é plausível supor que a ESF constitui o modelo normativo de atenção primária à saúde hegemônico nos municípios piauienses, pelo menos do ponto de vista formal. Por outra vertente, é também necessário, apesar da rápida expansão verificada, admitir que a implementação da ESF tenha ocorrido com formato e ritmo diversificados nos diferentes municípios, uns obtendo maiores coberturas e resultados, a partir do novo modelo assistencial de base comunitária, antes dos demais. Apesar da homogeneidade da presença da ESF, não se pode afirmar, a partir deste trabalho, a existência de padrões de acesso e qualidade no estado, mas certamente houve uma adesão total dos municípios piauienses à ESF, durante a década de 2000.

A PNAB 3, dimensão normativa da ESF, incluiu a saúde da criança dentre as linhas de cuidado desenvolvidas, abrangendo, de forma geral, o acompanhamento do desenvolvimento da criança, manejo clínico de doenças infecciosas prevalentes na infância, combate à desnutrição, além de ações de prevenção e promoção da saúde infantil e materna, tais como a imunização por vacinas, promoção do aleitamento materno e orientações às famílias sobre os cuidados com a criança, compondo um conjunto de intervenções efetivas para a melhoria da saúde infantil 23,24. Entretanto, essas ações consistem grupo de fatores que podem incidir nas condições de saúde, os quais se combinam com outras dimensões da vida social, a fim de produzir resultado sobre a qualidade de vida ligada à saúde 20 .

É preciso, pois, contextualizar sob o prisma socioeconômico a década analisada, a fim de não se perder o referencial das mudanças ocorridas fora dos serviços de saúde, as quais também influenciam a qualidade de vida da população infantil. Para tanto, pode-se lançar mão dos dados dos censos demográficos do IBGE dos anos de 2000 e 2010, identificando-se possíveis mudanças no cenário social piauiense, destacandose variáveis representativas, tais como o acesso a serviços básicos de saneamento ou níveis de escolaridade. Nesse aspecto, a escolaridade materna constitui fator especialmente impactante na saúde das crianças $25,26,27,28$. O Estado do Piauí, com efeito, apresentou mudanças importantes no período avaliado. Segundo os dados do Sistema de Informações sobre Nascidos Vivos (SINASC) do Ministério da Saúde 29, cotejandose apenas as informações dos anos 2000 e 2010, tem-se que, em 2000, 39,5\% das mães tinham baixo nível de escolaridade, com até 4 anos de estudos, ao passo que a faixa com escolaridade superior a 8 anos correspondia a 22,3\%. Já em 2010, as mães com até 4 anos de estudos correspondiam a $15,5 \%$ e aquelas com mais de 8 anos representavam 48,5\% dos registros de nascidos vivos no estado (IBGE; http://tabnet.datasus. gov.br/cgi/deftohtm.exe?sinasc/cnv/nvpi.def, acessado em 02/Set/2011), representando uma inversão positiva do perfil de escolaridade materna, segundo os registros do SINASC.

Tal evolução se confirma nos dados da Pesquisa Nacional por Amostra de Domicílios (PNAD) de 2009 29, se considerada a escolaridade da população feminina no estado. Embora com menores proporções que o SINASC, a PNAD apontou a redução relevante do porcentual na população feminina maior de 15 anos com menos de 4 anos de estudos e o aumento das faixas com escolaridade de 8 anos, considerando-se os anos de 2001-2009 29. Assim, mudanças no perfil materno possivelmente influenciaram, em alguma medida, as internações hospitalares em menores de 5 anos no Piauí, de 2000 a 2010, dado o aumento da escolaridade feminina no Piauí, tanto geral como materna.

Atendo-se apenas aos resultados do presente estudo, verificou-se redução do número de internações hospitalares em menores de 5 anos. Porém, também se observou a persistência de proporções significativas das hospitalizações relacionadas com doenças infecciosas e parasitárias e doenças do aparelho respiratório, em face do que, não se pode afirmar que houve mudanças profundas das importâncias relativas dessas internações no Estado do Piauí. Por outro lado, se identificou que, especificamente no ano de 2010 , as gastrenterites e as pneumonias permaneceram sendo as causas mais frequentes de internação hospitalar infantil no Piauí, correspondendo, respectivamente, a 32,6 e $12,8 \%$ do total das internações hospitalares registradas em menores de 5 anos.

Especificamente quanto ao cálculo das taxas de internação hospitalar nas faixas etárias analisadas, as estimativas intercensitárias mostraram-se superestimadas em face dos resultados do Censo Demográfico de 2010, não se podendo precisar a partir de quando essas projeções distanciaram-se de forma relevante da realidade. Com efeito, comparando-se o ano de 2009, quando a população por faixa etária se definiu por estimativa, com 2010, quando se deu o último censo demográfico, viu-se que a população de menores de 5 anos sofreu abrupta redução de $26,8 \%$, caindo de 315 para 247 mil crianças. Uma relevante discordância que reflete alguma imprecisão nas estimativas populacionais do período de 2001 a 2009 e levou a uma possível subestimação das taxas de internação a partir de algum momento da série histórica investigada. De toda maneira, considerou-se válido prosseguir esta análise de internações hospitalares como subsídio para a 
formulação de hipóteses acerca do impacto da ESF sobre a saúde infantil no Piauí.

Segundo as faixas etárias específicas analisadas, as doenças do aparelho respiratório mantiveram-se como o grupo de causas mais relevante na hospitalização de crianças até 1 ano de idade, mas com redução importante da frequência e das taxas de internação. Já as afecções perinatais apresentaram aumento nas taxas e proporção, e passaram a disputar com as doenças infecciosas e parasitárias a segunda posição proporcional nas internações hospitalares de menores de 1 ano, na série histórica analisada.

As afecções perinatais figuram como o principal grupo de causas dos óbitos neonatais no Brasil 30 e representam, na sua maior parte, problemas relacionados com a qualidade da assistência pré-natal, a qual consiste atribuição da ESF, mas também ao parto e neonato, de competência dos serviços hospitalares. De todo modo, as internações relacionadas com as afecções perinatais, assim com os eventuais óbitos daí advindos, dos quais este estudo não trata, em princípio, podem ser considerados evitáveis na sua maior parcela 30 .

Nas hospitalizações de crianças de 1-4 anos, observaram-se vários aspectos similares à faixa etária anterior. Houve efetiva redução da frequência e taxas de hospitalização, especialmente no grupo de causas ligadas às doenças infecciosas e parasitárias, mas as mudanças mostraram-se menos profundas nas proporções destas internações. As doenças infecciosas e parasitárias continuaram, ao longo da década analisada, correspondendo à parcela mais significativa das internações hospitalares na faixa etária de 1-4 anos, ao passo que as doenças do aparelho respiratório pouco foram reduzidas em termos absolutos e ainda tiveram aumentada sua importância proporcional. As doenças do aparelho de digestivo, por sua vez, cresceram em importância proporcional, dado que sua frequência também apresentou tendência incremental ao longo da década.

De uma forma geral, nas faixas etárias investigadas, a correlação da evolução das taxas de internação nos grupos de causas mais importantes e o avanço da cobertura estimada da ESF mostrou-se forte, representando que a redução do número de internações seguiu, em princípio, o mesmo ritmo, fundamentando a hipótese de que as internações hospitalares foram influenciadas pela expansão da atenção primária à saúde no estado.

Entretanto, a persistência dos maiores porcentuais de internação por grupos de causas segundo os capítulos da CID-10, em menores de 5 anos, mostra que as mudanças podem não ter sido tão significativas. No Brasil, as três principais causas de ICSAP nas faixas etárias de menores de 5 anos no período de 1999 a 2006 foram: gastrenterites infecciosas, pneumonias bacterianas e asma, para menores de 1 ano de idade, e gastrenterites infecciosas, asma e pneumonias bacterianas, para crianças de 1-4 anos 15. Embora não se possam comparar os resultados nacionais aos aqui apresentados, ainda assim é possível refletir sobre o cenário piauiense.

A prevalência das internações devidas a doenças, em princípio, tratáveis no nível ambulatorial em ambas as faixas etárias investigadas, inspira a discussão sobre as potenciais barreiras de acesso e qualidade do cuidado ambulatorial no Piauí. A ampliação do acesso à atenção primária à saúde está, de forma geral, associada à diminuição das taxas de internação hospitalar 31, mas estas também podem ser influenciadas por fatores socioeconômicos, ambientais e biológicos, além da disponibilidade de recursos e pela prática clínica dos médicos, que podem apresentar maior ou menor disposição para a hospitalização de quadros tratáveis em nível primário, dependendo do contexto 32 .

Este trabalho se teve em conta, sem se desconsiderar o relevante papel que fatores socioeconômicos e ambientais possam desempenhar 33, que algumas internações hospitalares guardam estreita associação com o acesso e a qualidade no nível primário da atenção à saúde 9,18,19,20,21,22. Assim, da mesma forma que a redução das internações hospitalares mostrou potencial relação com a ampliação do acesso no Piauí, a manutenção de taxas elevadas de hospitalização e suas proporções representam a persistência do deslocamento do cuidado para o nível hospitalar, refletindo potenciais barreiras de acesso e limitações à resolutividade dos serviços de atenção primária à saúde no estado.

Daí, a análise do ano de 2010 quanto ao perfil das internações hospitalares entre crianças no Piauí, pode subsidiar hipóteses acerca da resolutividade do cuidado ambulatorial no estado. Verificou-se que os grupos de causas da lista brasileira de ICSAP mais relevantes nas internações de menores de 5 anos, em 2010, foram: gastrenterites infecciosas (Grupo 2), pneumonias bacterianas (Grupo 6) e asma (Grupo 7). Tal resultado parece guardar coerência com a tendência nacional, embora apresente taxas de internação mais elevadas em todos os grupos de causas, mesmo considerando-se o cenário brasileiro de 200615. Enquanto as taxas nacionais de internação por gastrenterites infecciosas de menores de 1 ano e de 1-4 anos, em 2006, respectivamente, foram de 267,2 e 130,7 15, o Piauí apresentou taxa para menores de 5 anos no mesmo grupo de causas, 
já em 2010, de 334,6. As pneumonias bacterianas apresentaram, por sua vez, em 2010, taxa de 131,2 e a asma de 55,6, aproximando-se, assim, das médias nacionais apontadas em 200615.

Embora tratando-se de períodos e escalas diferentes, é plausível que o Brasil tenha reduzido suas taxas médias, se comparados os anos de 2010 e 2006, uma vez que se tenha mantida a tendência de declínio ${ }^{15}$. Isso poderia representar também um acirramento da clivagem entre o cenário piauiense e a média nacional, já que o Piauí apresentaria situação menos favorável quanto às ICSAP em menores de 5 anos de idade, especialmente por gastrenterites infecciosas, não obstante sua cobertura populacional estimada de atenção primária à saúde de 97,2\%.

Embora não se possa compreender o perfil das ICSAP no Piauí somente com base na dimensão assistencial, sendo improvável que os resultados, tanto os positivos quanto os negativos, se correlacionem única e diretamente à presença da ESF no estado, é admissível que os limites dos impactos da atenção primária à saúde sobre a saúde infantil sejam tanto maiores quanto forem as barreiras ao acesso e à melhoria da qualidade da atenção realizada.

Em síntese, o Piauí apresentou a larga expansão proporcional da ESF ao longo da década de 2000, alcançando a maior cobertura populacional estimada do país $(97,2 \%)$. Nesse mesmo período, observou-se a redução geral da frequência e taxas das internações hospitalares de menores de 5 anos, sendo o declínio mais favorável nas hospitalizações causadas por doenças infecciosas e parasitárias (capítulo I da CID-10) do que nos outros dois principais grupos de causa de internação, doenças do aparelho respiratório (capítulo X da CID-10) e doenças do aparelho digestivo (capítulo XI da CID-10). Em termos proporcionais, entretanto, as causas de hospitalização infantil mais frequentes persistiram, ou mesmo aumentaram, como nas internações por afecções perinatais em menores de 1 ano e doenças do aparelho respiratório em crianças de 1-4 anos. Por outro lado, as taxas de ICSAP entre menores de 5 anos, em 2010, ainda foram elevadas nos três grupos de causas de hospitalização mais frequentes, em especial por gastrenterites infecciosas, mas também por pneumonias bacterianas e asma.

A associação entre a evolução das internações hospitalares infantis e a expansão da cobertura populacional estimada da ESF no estado mostrou-se plausível, especialmente internações relacionadas às doenças infecciosas e parasitárias e do aparelho respiratório. Entretanto, as taxas de internação permaneceram elevadas, representando a necessidade de se avaliar melhor as limitações dos resultados da ESF nos municípios do Piauí, suas relações com o contexto socioeconômico, ambiental e cultural, bem como disponibilidade de recursos, estruturas disponíveis e arranjos organizacionais.

Novas avaliações poderiam também incluir análises qualitativas sobre os recursos disponíveis, estruturas e processos de trabalho, considerando a heterogeneidade dos cenários municipais, a fim de que se possa compreender melhor os impactos da ESF no Piauí, em especial sobre a saúde infantil. 


\section{Resumo}

Internações hospitalares por algumas condições de saúde podem ser reduzidas por uma atenção primária oportuna e com qualidade, especialmente na população infantil. Analisou-se a evolução das internações hospitalares de menores de 5 anos no Piauí, Brasil, de 2000 a 2010, segundo grupos de causas (CID-10) $e$ das internações de 2010, com base na lista brasileira de Internações por Condições Sensíveis à Atenção Primária. O objetivo foi identificar mudanças no perfil de morbidade hospitalar e discutir sua relação com a expansão da ESF no estado. O Piauí apresentou a maior expansão proporcional da ESF, alcançando a cobertura estimada de 97,2\%, em 2010. No período de 2000 a 2010, a frequência e as taxas de internações em menores de 5 anos foram reduzidas, porém, a proporção de hospitalizações nos principais grupos de causas se manteve ou aumentou, ao longo da década analisada. Em 2010, 60\% das internações em menores de 5 anos foram por causas sensíveis à atenção primária, em especial gastrenterites infecciosas, infecções respiratórias e asma.

Atenção Primária à Saúde; Hospitalização; Saúde da Criança

\section{Colaboradores}

J. O. M. Barreto concebeu a ideia e a metodologia, coletou e analisou os dados e redigiu a primeira versão do texto. I. S. Nery revisou o texto e inseriu alterações relevantes. M. S. C. Costa redigiu com J. O. M. Barreto a primeira versão do texto.

\section{Referências}

1. Declaration of Alma-Ata. In: International conference on primary health care. http://who.int./hpr/ $\mathrm{NPH} /$ doc/declaration_almaata.pdf (acessado em 23/Ago/2011).

2. Starfield B. Atenção primária: equilíbrio entre necessidades de saúde, serviços e tecnologia. Brasília: Organização das Nações Unidas para Educação, a Ciência e Cultura/Ministério da Saúde; 2004.

3. Ministério da Saúde. Política Nacional de Atenção Básica. Brasília: Ministério da Saúde; 2006.

4. Ministério da Saúde. Saúde da família: uma estratégia para a reorientação do modelo assistencial. Brasília: Ministério da Saúde; 1998.

5. Harzheim E, Stein AT, Álvarez-Dardet C. A efetividade dos atributos da atenção primária sobre a saúde infantil. Boletim da Saúde 2004; 18:23-40.

6. Macinko J, Guanais FC, Souza MFM. Evaluation of impact of the Family Health Program on infant mortality in Brazil, 1990-2002. J Epidemiol Community Health 2006; 60:13-9.
7. Duarte CMR. Reflexos das políticas de saúde sobre as tendências da mortalidade infantil no Brasil: revisão da literatura sobre a última década. Cad Saúde Pública 2007; 23:1511-28.

8. Sousa MF. O Programa de Saúde da Família no Brasil: análise de acesso à atenção básica. Rev Bras Enferm 2008; 61:153-8.

9. Aquino R, Oliveira NF, Barreto ML. Impact of the Family Health Program on infant mortality in Brazilian Municipalities. Am J Public Health 2008; 99:87-93.

10. Sousa A, Hill K, Dal-Poz MR. Sub-national assessment of inequality trends in neonatal and child mortality in Brazil. Int J Equity Health 2010: 9-21.

11. Bonnefoy C, Armijo M. Indicadores de desempeño en el sector público. Santiago de Chile: Instituto Latinoamericano y del Caribe de Planificación Económica y Social; 2005.

12. Jannuzzi PM. Considerações sobre o uso, mau uso e abuso dos indicadores sociais na formulação e avaliação de políticas públicas municipais. Revista do Serviço Público 2002: 36:51-72. 
13. Fernandes VBL, Caldeira AP, Faria AA, Rodrigues Neto JF. Internações por condições sensíveis. Rev Saúde Pública 2009; 43:928-36.

14. Malta DC, Duarte EC, Almeida MF. Lista de causas de mortes evitáveis por intervenções do Sistema Único de Saúde do Brasil. Epidemiol Serv Saúde 2007; 16:233-44.

15. Moura BLA, Cunha RC, Aquino R, Medina MG, Mota ELA, Macinko J, et al. Principais causas de internação por condições sensíveis à atenção primária no Brasil: uma análise por faixa etária e região. Rev Bras Saúde Matern Infant 2010; 10 Suppl 1:S83-91.

16. Caminal Homar J, Morales Espinoza M, Sánchez Ruiz E, Cubells Larrosa MJ, Bustins Poblet M. Hospitalizaciones prevenibles mediante una atención primaria oportuna y efectiva. Aten Primaria 2003; 31:6-17.

17. Márquez-Calderón S, Rodríguez del Águila MM, Perea-Milla E, Ortiz J, Bermúdez-Tamayo C. Factores asociados a la hospitalización por procesos sensibles a cuidados ambulatorios en los municipios. Gac Sanit 2003; 17:360-7.

18. Alfradique ME, Bonolo PF, Dourado I, Lima-Costa MF, Macinko J, Mendonça CS, et al. Internações por condições sensíveis à atenção primária: a construção da lista brasileira como ferramenta para medir o desempenho do sistema de saúde (Projeto ICSAP - Brasil). Cad Saúde Pública 2009; 25:1337-49.

19. Ministério da Saúde. Portaria no ${ }^{\circ}$ 221, de 17 de abril de 2008. http://dtr2001.saude.gov.br/sas/ PORTARIAS/Port2008/PT-221.htm (acessado em 20/Abr/2011).

20. Comissão Nacional sobre Determinantes Sociais da Saúde. Relatório final. http://www.determi nantes.fiocruz.br/comissao.asp (acessado em 15/ Abr/2011).

21. Agência Nacional de Saúde Suplementar. Dados e indicadores do setor. http://www.ans.gov.br/ index.php/materiais-para-pesquisas/perfil-dosetor/dados-e-indicadores-do-setor (acessado em 27/Ago/2011).

22. Instituto Brasileiro de Geografia e Estatística. Est@ dos - mapa da pobreza e desigualdade - municípios brasileiros 2003. http://www.ibge.gov.br/es tadosat $/$ temas.php?sigla=pi\&tema=mapapobreza 2003 (acessado em 27/Ago/2011).

23. Saugar GC, Santamera AS. Evaluación de intervenciones para la reducción de la mortalidad infantil y materna en países en desarrollo. Madrid: Agencia de Evaluación de Tecnologías Sanitarias, Instituto de Salud Carlos III; 2008.
24. World Health Organization. Countdown to 2015 decade report (2000-2010): taking stock of maternal, newborn and child survival. http://www.count down2015mnch.org/reports-publications/2010report (acessado em 02/Set/2011).

25. Caetano JRM, Bordin IAS, Puccini RF, Peres CA. Fatores associados à internação hospitalar de crianças menores de cinco anos, São Paulo, SP. Rev Saúde Pública 2002; 36:285-91.

26. Geib LTC, Freu CM, Brandão M, Nunes ML. Determinantes sociais e biológicos da mortalidade infantil em coorte de base populacional em Passo Fundo, Rio Grande do Sul. Ciênc Saúde Coletiva 2010; 15:363-70.

27. Lasmar L, Goulart E, Sakurai E, Camargos P. Fatores de risco para hospitalização de crianças e adolescentes asmáticos. Rev Saúde Pública 2002; 36:409-19.

28. Prietsch SOM, Fischer GB, César JA, Lempek BS, Barbosa Jr. LV, Zogbi L, et al . Acute lower respiratory illness in under-five children in Rio Grande, Rio Grande do Sul State, Brazil: prevalence and risk factors. Cad Saúde Pública 2008; 24:1429-38.

29. Instituto Brasileiro de Geografia e Estatística. Pesquisa Nacional de Amostras de Domicílios, 2001 a 2009. http://www.sidra.ibge.gov.br/pnad/default. asp (acessado em 02/Set/2011).

30. Ministério da Saúde. Manual dos Comitês de prevenção do óbito infantil e fetal. Brasília: Ministério da Saúde; 2009.

31. Laditka JN, Laditka SB, Probst JC. More may be better: evidence of a negative relationship between physician supply and hospitalization for ambulatory care sensitive conditions. Health Serv Res 2005; 40:1148-66.

32. Komaromy M, Lurie N, Osmond D, Vranizan K, Keane D, Bindman A. Physician practice style and rates of hospitalization for chronic medical conditions. Med Care 1996; 34:594-609.

33. Genser B, Strina A, dos Santos LA, Teles CA, Prado MS, Cairncross S, et al. Impact of a city-wide sanitation intervention in a large urban centre on social, environmental and behavioural determinants of childhood diarrhoea: analysis of two cohort studies. Int J Epidemiol 2008; 37:831-40.

Recebido em 07/Mai/2011

Versão final reapresentada em 11/Set/2011 Aprovado em 20/Out/2011 